\title{
The Serum Level of Leptin in Patients with Obesity: Asthmatic and Non-Asthmatic Children
}

\author{
Maryam Alamzadeh,, Zahra Chavoshzadeh,, Mohammadreza Alaei, ${ }^{3}$ Mahboubeh Mansouri, ${ }^{4}$ \\ Eznollah Azargashb, ${ }^{5}$ Maryam Boloursaz, ${ }^{6}$ and Sepideh Darougar ${ }^{6, *}$ \\ ${ }^{1}$ Mofid's Children Hospital, Shahid Beheshti University of Medical Sciences, Tehran, Iran \\ ${ }^{2}$ Pediatric Infectious Research Center, Mofid's Children Hospital, Shahid Beheshti University of Medical Sciences, Tehran, Iran \\ ${ }^{3}$ Pediatric Endocrinology and Metabolism, Mofid Children's Hospital, Shahid Beheshti University of Medical Sciences, Tehran, Iran \\ ${ }^{4}$ Department of Immunology and Allergy, Mofid's Children Hospital, Shahid Beheshti University of Medical Sciences, Tehran, Iran \\ ${ }^{5}$ Department of Community Medicine, Faculty of Medicine, Shahid Beheshti University of Medical Sciences, Tehran, Iran \\ ${ }^{6}$ Pediatric Respiratory Diseases Research Center, National Research Institute of Tuberculosis and Lung Diseases (NRITLD), Shahid Beheshti University of Medical Sciences, \\ Tehran, Iran \\ "Corresponding author: Sepideh Darougar, Dr. Masih Daneshvari Hospital, Darabad Avenue, Shahid Bahonar Roundabout, Tehran, Iran. Tel: +98-9122881975, Fax: \\ +98-2126109490, E-mail: sepidehdarougar@yahoo.com
}

Received 2017 January 18; Revised 2017 February 19; Accepted 2017 February 20.

\begin{abstract}
Background: Leptin is a pro-inflammatory cytokine produced by adipose tissue. Considering the association between obesity and asthma, the current study aimed at investigating if leptin was in the pathway of obesity-asthma relationship in children and if it played a distinctive role in children with asthma and obesity versus the ones with obesity but without asthma.

Methods: The current case-control study was conducted on 23 children with asthma and obesity and 13 children with obesity but without asthma (body mass index $\geq 95 \%$ ) aged 6 to 15 years from October 2011 to October 2012 in Mofid Children's Hospital, Tehran, Iran. Group 1 included 23 children with asthma and obesity with a mean BMI of $24.3 \mathrm{~kg} / \mathrm{m}^{2}$, while group 2, included 13 cases with obesity but without asthma and a mean BMI of $26.6 \mathrm{~kg} / \mathrm{m}^{2}$. Both groups were evaluated for their serum leptin, triglyceride, cholesterol, and IgE mean levels. The serum leptin levels were measured by the enzyme-linked immunosorbent assay (ELISA) technique. The results were analyzed with SPSS version 19. The Mann-Whitney test was employed to compare the results.

Results: The mean serum leptin level in the children with asthma and obesity was $2.19 \mathrm{ng} / \mathrm{mL}$ and in the ones with obesity but without asthma was $2.85 \mathrm{ng} / \mathrm{mL}(\mathrm{P}=0.006)$. The mean serum triglyceride and cholesterol levels in the group 1 were $175.4 \mathrm{mg} / \mathrm{dL}$ and $189 \mathrm{mg} / \mathrm{dL}$, respectively, while in the group 2 were $175.4 \mathrm{mg} / \mathrm{dL}$ and $226.2 \mathrm{mg} / \mathrm{dL}$, respectively. A significant difference was observed in serum leptin levels between the children in groups 1 and $2(\mathrm{P}=0.006)$, but surprisingly the increased leptin was detected in the group 2 subjects.

Conclusions: The current study findings indicated that serum levels of leptin were significantly higher in the cases with obesity but without asthma. Therefore, other cytokines appeared to play a role in the children with asthma and obesity.
\end{abstract}

Keywords: Obesity, Asthma, Leptin, Children, Adipose Tissue

\section{Background}

There was a parallel increase in emerging obesity and development of asthma during the past decades (1). An association between obesity and asthma was shown in several studies (2), but the underlying mechanisms are not yet established. However, several mechanisms were postulated previously. It is proposed that genetic and environmental factors may increase the risk of obesity and asthma, concurrently (3). Furthermore, obesity may increase the risk of sleep-disordered breathing and gastroesophageal reflux disorder (4) both associated with an increased risk of asthma (5). In addition, obesity influences mechanical factors such as lung volume and airway diameter by reducing them, thereby, inducing asthma development (6). One of the most recent hypothesis regarding the devel- opment of asthma in patients with obesity considers cytokines, chemokines, acute phase proteins and energy regulating hormones including serum leptin (7). These mediators are produced by adipocytes. Leptin is a protein synthesized through the expression of obesity gene acting as an energy regulating hormone derived from adipose tissues (3).

Many effects are attributed to leptin. Circulating leptin is positively correlated with body fat mass. Among other functions considered for leptin, primary effects on energy regulation by inhibiting food intake and increased energy expenditure are the important factors regarding obesity. Pro-inflammatory properties were also identified by the stimulation of tumor necrosis factor (TNF)- $\alpha$ and interleukin (IL)-6 from the adipose tissue (8). It is observed that 
leptin promotes Th1 immune responses with increased production of IFN-Y (3). TNF- $\alpha$ and IFN-Y are the mediators associated with airway hyper-responsiveness in asthma. IL6 plays a role in the expansion of Th2 and Th17 cells, and therefore, has a pro-inflammatory effect in asthma (9). Despite all inconsistencies, the relationship between obesity and occurrence of asthma in children and adults is demonstrated in several studies. Leptin is proposed as an obesity gene product with a role in asthma-obesity relationship (3).

The current study aimed at evaluating the role of leptin in obesity-related asthma in pediatric age groups. The current study addressed the role of leptin, by comparing the serum leptin level in children with obesity with/without asthma.

\section{Methods}

The current case-control study was funded by the infectious research center of Mofid university hospital, at outpatient clinics of asthma and endocrine diseases, affiliated to Shahid Beheshti University of Medical Sciences, Tehran, Iran, from October 2011 to October 2012

The study included 36 subjects referred to endocrine clinic for obesity and were classified into 2 groups of children with obesity with and without asthma according to GINA 2011 (10). Group 1 included 23 cases with obesity and asthma (cases) with a mean body mass index (BMI) of 24.3 $\mathrm{kg} / \mathrm{m}^{2}$, and group 2 included 13 children with obesity (controls) and a mean BMI of $26.6 \mathrm{~kg} / \mathrm{m}^{2}$, apparently healthy without a diagnosis of any disorders including asthma. Both groups were evaluated for their serum leptin, triglyceride, and cholesterol. Serum IgE level was measured only in the group 1 cases. Obesity or increased adiposity was defined using BMI.

BMI was calculated as weight ( $\mathrm{kg}$ ) divided by height (m) squared. According to this calculation, children $>2$ years old, with a BMI $\geq 95$ th percentile met the criterion for obesity and those with a BMI between the 85th and 95th percentiles fell in the overweight range (11). BMI-for-age profiles for males and females were developed by the national center for health statistics in collaboration with the national center for chronic disease prevention and health promotion (2000), www.cdc.gov/growthcharts. Inclusion criteria were the patients with asthma (according to GINA 2011 criteria) (10), aged 6 to 15 years, for at least 3 months well-controlled on inhaled corticosteroids with a BMI of 95th percentile or greater. Well-controlled asthma was considered as an inclusion criteria for the patients to minimize the possible confounding effects. Therefore, patients with asthma receiving systemic steroids in the preceding
4 weeks were excluded from the study. Serum leptin does not seem to be affected by inhaled corticosteroids $(12,13)$.

Individuals with known infectious, cardiovascular, rheumatic, malignancy, liver, and kidney disorders were excluded from the study.

All patients were subjected to:

1) Full medical history including breathlessness, chest tightness, wheezing and cough, family history of asthma or atopic diseases, and comorbid disorders.

2) Complete physical examination including general examination and also chest examination. Their weight and height were measured in kilogram and meters, respectively, and then, BMI was calculated accordingly.

3) Full conventional laboratory investigations (including complete blood test (CBC), IgE, triglyceride, and cholesterol). Serum concentrations of total cholesterol and triglycerides were measured by enzymatic calorimetric methods (Pars Azmoon kits, Iran). Serum IgE level was assessed by the enzyme-linked immunosorbent assay (ELISA) technique.

4) Two phase spirometry (FEV1/FVC ratio $<0.75-0.8$ in addition to the degree of reversibility to bronchodilators) when possible, according to age.

5) Measurement of serum leptin level. Fasting venous samples were collected at 8:00 AM. After centrifuging at $4^{\circ} \mathrm{C}$, measurement of serum leptin was done for both groups of individuals (cases and controls) by ELISA (Mediagnost, Human Leptin, Germany) based on the manufacturer's guidelines.

An informed consent was taken from the subjects' caregivers before enrolling the children in the study. Therefore, all the cases and also the controls participated in the current study with their parents' decision. All of the participants received their test results. During the study, nobody received additional therapies, and nobody was deprived from the necessary therapies.

\subsection{Statistical Analysis}

Numerical variables were expressed as mean \pm standard variable (SD). Numerical parameters with abnormal distribution (serum leptin and IgE levels) were reported as medians. The analysis was evaluated by the Mann-Whitney test. Statistical analysis was performed with the SPSS version 19 for windows. P value $<0.05$ was considered significant.

\section{Results}

Demographic and laboratory data obtained from the 2 groups are demonstrated in Tables 1 and 2. 
Table 1. Descriptive Statistics in the Subjects with Obesity and Without Asthma

\begin{tabular}{|c|c|c|c|c|c|}
\hline & $\mathbf{N}$ & Minimum & Maximum & Mean & Std. Deviation \\
\hline Age (year) & 13 & 6 & 13 & 9.23 & 2.279 \\
\hline Weight (kg) & 13 & 31 & 85 & 49.92 & 19.268 \\
\hline Height $(\mathrm{cm})$ & 13 & 114 & 158 & 134.62 & 13.973 \\
\hline $\operatorname{BMI}\left(\mathrm{kg} / \mathrm{m}^{2}\right)$ & 13 & 21.0 & 34.9 & 26.562 & 4.7243 \\
\hline BMI percentile & 13 & 99.2 & 99.9 & 99.669 & 0.3038 \\
\hline Leptin level (ng/mL) & 13 & 2.136 & 3.327 & 2.85069 & 0.398916 \\
\hline Triglyceride (mg/dL) & 13 & 100 & 250 & 175.46 & 43.906 \\
\hline Cholesterol (mg/dL) & 13 & 154 & 320 & 226.23 & 62.250 \\
\hline Valid N(listwise) & 13 & & & & \\
\hline
\end{tabular}

Table 2. Descriptive Statistics in the Study Subjects With Obesity Asthma

\begin{tabular}{|c|c|c|c|c|c|}
\hline & $\mathbf{N}$ & Minimum & Maximum & Mean & Std. Deviation \\
\hline Age (year) & 23 & 6 & 15 & 8.52 & 2.626 \\
\hline Weight (kg) & 23 & 30 & 77 & 45.48 & 13.460 \\
\hline Height $(\mathrm{cm})$ & 23 & 116 & 160 & 135.39 & 11.512 \\
\hline BMI $\left(\mathrm{kg} / \mathrm{m}^{2}\right)$ & 23 & 19.2 & 32.3 & 24.300 & 3.6643 \\
\hline BMI percentile & 23 & 96.8 & 99.9 & 99.452 & 0.8062 \\
\hline Leptin level (ng/mL) & 23 & 0.709 & 3.254 & 2.18757 & 0.768159 \\
\hline Triglyceride (mg/dL) & 23 & 61 & 343 & 175.39 & 67.212 \\
\hline Cholesterol (mg/dL) & 23 & 148 & 244 & 189.78 & 24.045 \\
\hline IgE level (IU/L) & 23 & 11 & 126 & 47.91 & 38.181 \\
\hline Valid N(leastwise) & 23 & & & & \\
\hline
\end{tabular}

Nine of the total studied population was female and the remaining 27 were male. Among the subjects participated in the study, 4 females and 19 males had asthma. The mean serum leptin level in the group 1 was $2.19 \mathrm{ng} / \mathrm{mL}$ versus $2.85 \mathrm{ng} / \mathrm{mL}$ in the group 2.

The current study compared serum cholesterol and triglycerides in the subjects with obesity and asthma and the ones with obesity but without asthma; no significant difference was observed between the 2 studied parameters in the study groups $(\mathrm{P}>0.05)$. However, a significant difference was observed in serum leptin levels between the children with obesity with and without asthma ( $\mathrm{P}=$ 0.006) (Table 3), but surprisingly the increased leptin was detected in the group 2 cases with a slightly higher mean BMI (Figure 1).

\section{Discussion}

The current study investigated the role of leptin in the development of asthma in children with obesity. Obesity is increasingly accounted as a risk factor for asthma $(14,15)$. It seems that the association between obesity and asthma is complex and multifaceted and is likely explained by many mechanisms. Recently, a distinctive role is suggested for leptin in the prognosis of asthma in patients with obesity and also a link between leptin and asthma is suggested by some studies $(3,16,17)$.

The role of adipose tissue in the development or worsening of asthma among individuals with obesity is the subject of multiple recent reviews. Adipose tissue is an active endocrine organ, producing energy regulating hormones such as leptin. In obesity, serum concentrations of leptin increases and the adipose tissue of individuals with obesity is infiltrated with activated macrophages. It is suggested that during the development of obesity, hypertrophy of the adipose tissue results in local tissue hypoxia, adipocyte necrosis, and macrophage recruitment. These factors, in association with each other, lead to toll-like receptor signaling via fatty acids, and subsequently, result in the gen- 
Table 3. PValue for BMI, Leptin, Triglyceride and Cholesterol obtained by Mann-Whitney Test

\begin{tabular}{|c|c|c|c|c|}
\hline & BMI & Leptin Level & TG & Cholesterol \\
\hline Mann-whitney U & 102.500 & 68.500 & 144.500 & 103.500 \\
\hline Wilcoxon W & 378.500 & 344.500 & 420.500 & 379.500 \\
\hline $\mathbf{Z}$ & -1.548 & -2.668 & -0.165 & -1.516 \\
\hline Asymp. Sig. (2-tailed) & 0.122 & 0.008 & 0.869 & 0.130 \\
\hline
\end{tabular}

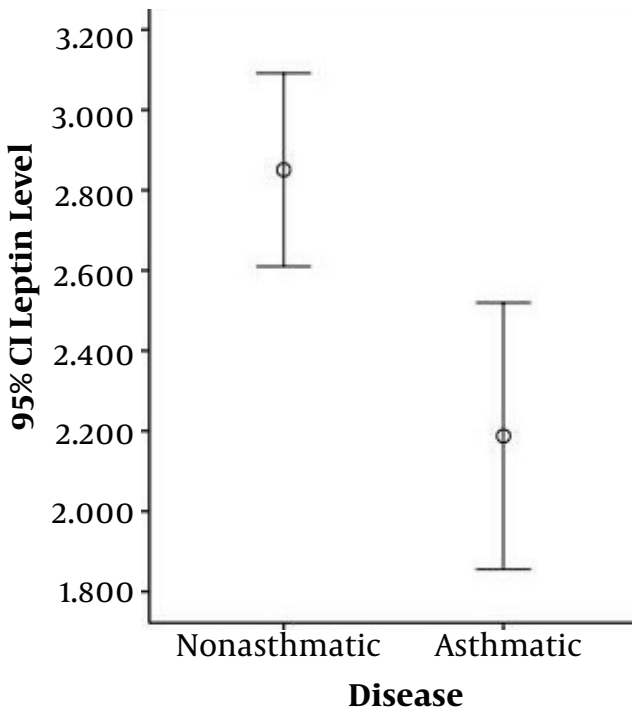

Figure 1. A Comparison of Serum Leptin Levels Between the Children with Obesity and Asthma and Their Counterparts with Obesity Without Asthma

eration and release of a variety of pro-inflammatory cytokines, chemokines, acute phase reactants, and leptin.

Leptin is a 16-kD protein derived from the obese gene and is expressed predominantly in adipocytes (16). It is considered that many factors affecting the serum leptin level including gender, age, puberty, BMI, breast feeding, and steroid therapy $(12,18,19)$. The possible role of leptin in airway inflammation was studied in animal models. Shore demonstrated that administration of exogenous leptin to the leptin-deficient mice augmented the pulmonary inflammation (20), but this association was unlikely due to a direct effect of leptin as a pro-inflammatory cytokine on airway smooth muscle (21). However, the exact relationship between leptin and asthma is still unknown in children and adults. Various results from different studies, sometimes in great conflict with each other, were reported. One of these studies, performed by Sutherland et al., demonstrated that leptin was unlikely to mediate the association between asthma and obesity (22).

It is known well that obesity has complex influences on allergic inflammation and is likely an important modifier of the pathogenesis of airway disease in asthma (17). Conversely, Dixon suggested that although the individuals with obesity and asthma may have signs of Th2-mediated inflammation, adipokine derangements in obesity are associated with Th1 rather than Th2 bias (23).

In an animal model experiment, allergen sensitized and challenged mice that underwent continuous infusion of leptin. Leptin had no effect on airway responsiveness in unchallenged mice, but increased allergen induced airway hyper-responsiveness. Data on inflammatory outcomes in human studies are very limited. Since there are no interventional studies on this association, the causation of this association cannot be definitely established.

The current study found no evidence of an association between serum leptin levels and obesity-related asthma. In fact, serum leptin level was even higher in group 2 cases. Lacking any associations between serum leptin and asthma were previously demonstrated by Sutherland et al., in a population-based birth cohort of approximately 1000 young adult (22), and by Jartti et al. (24), in a large sequential, cross sectional study set within an established Finnish cohort. Another small clinic-based, case-control study by Holguin et al., showed no associations between serum leptin and lung inflammatory biomarkers in 48 studied subjects, of whom $44 \%$ had asthma and $56 \%$ were healthy controls. Among subjects with asthma in their study, $66 \%$ had obesity, $10 \%$ overweight, and $24 \%$ lean. Kim et al., did not find a link between leptin and asthma in children (25). Among individuals with atopic asthma, transient provocations from an inhalational allergen challenge did not affect serum leptin concentrations (26). In a cross sectional study by Guler et al., higher leptin levels were found in the children with asthma, compared with their counterparts without asthma, but the adjustment for serum leptin levels did not affect the association between BMI and asthma, implying that the relationship between obesity and asthma was not mediated via leptin (27). The current study interestingly found out that serum leptin concentration was 
even significantly lower in the group 1 than the group 2 and the observed difference in leptin values had no clinical relevance. The current study results were against the conclusion that leptin appears to be an intermediary factor to explain the obesity-asthma association. The evidence for any possible link between leptin and obesity-associated asthma in the current study was weak and not convincing. However, it is believed that the small size of the population in the current study was its major limitation. Based on the fact that asthma is actually a syndrome with different pathological pathways leading to similar clinical presentations, the significance of patient-related contributing factors such as age, gender, fat distribution in the body, atopy, and comorbidities are highlighted, which their detailed effects cannot be overlooked. As a matter of fact, the current study suggested that while the causal pathway remains unknown, other metabolic pathways, mechanical factors, and also other cytokines rather than leptin alone may contribute to the obesity-asthma association.

\subsection{Conclusion}

The current study did not support a significant role for leptin in the development of obesity-associated asthma. It seems that the effect of BMI on asthma is not mediated by leptin pathway alone, but also involves other mechanistic and pathophysiologic pathways. Indeed, other contributory effects should not be overlooked.

\section{Acknowledgments}

The current study was supported by grant from infectious research center of Mofid hospital affiliated to Shahid Beheshti University of Medical Sciences. This article has been extracted from the thesis written by Dr. Maryam Alamzadeh in School of Medicine, Shahid Beheshti University Of Medical Sciences (Registeration number 229).

\section{Footnote}

Conflict of Interest: Authors declared no conflict of interest.

\section{References}

1. Chinn S, Rona RJ. Can the increase in body mass index explain the rising trend in asthma in children? Thorax. 2001;56(11):845-50. [PubMed: 11641508].

2. Chinn S. Obesity and asthma: evidence for and against a causal relation. J Asthma. 2003;40(1):1-16. [PubMed: 12699207].

3. Mai XM, Chen Y, Krewski D. Does leptin play a role in obesity-asthma relationship? Pediatr Allergy Immunol. 2009;20(3):207-12. [PubMed: 19455721].
4. Mai XM, Becker AB, Sellers EA, Liem JJ, Kozyrskyj AL. The relationship of breast-feeding, overweight, and asthma in preadolescents. $\mathrm{J}$ Allergy Clin Immunol. 2007;120(3):551-6. doi: 10.1016/j.jaci.2007.05.004. [PubMed: 17586035].

5. Hancox RJ, Poulton R, Taylor DR, Greene JM, McLachlan CR, Cowan JO, et al. Associations between respiratory symptoms, lung function and gastro-oesophageal reflux symptoms in a population-based birth cohort. Respir Res. 2006;7:142. doi: 10.1186/1465-9921-7-142. [PubMed: 17147826].

6. Beuther DA, Weiss ST, Sutherland ER. Obesity and asthma. Am J Respir Crit Care Med. 2006;174(2):112-9. doi: 10.1164/rccm.200602231PP. [PubMed:16627866].

7. Scherer PE. Adipose tissue: from lipid storage compartment to endocrine organ. Diabetes. 2006;55(6):1537-45. doi: 10.2337/db06-0263. [PubMed: 16731815].

8. Bastard JP, Maachi M, Lagathu C, Kim MJ, Caron M, Vidal H, et al. Recent advances in the relationship between obesity, inflammation, and insulin resistance. Eur Cytokine Netw. 2006;17(1):4-12. [PubMed: 16613757].

9. Barnes PJ. The cytokine network in asthma and chronic obstructive pulmonary disease. J Clin Invest. 2008;118(11):3546-56. doi: 10.1172/JCI36130. [PubMed: 18982161].

10. Pedersen SE, Hurd SS, Lemanske RJ, Becker A, Zar HJ, Sly PD, et al. Global strategy for the diagnosis and management of asthma in children 5 years and younger. Pediatr Pulmonol. 2011;46(1):1-17. doi: 10.1002/ppul.21321. [PubMed: 20963782].

11. Sheila G. Overweight and obesity. Canada: Elsevier; 2016

12. Gurkan F, Atamer Y, Ece A, Kocyigit Y, Tuzun H, Mete N. Serum leptin levels in asthmatic children treated with an inhaled corticosteroid. Ann Allergy Asthma Immunol. 2004;93(3):277-80.

13. Radetti G, Paganini C, Morpurgo PS, Pescollderungg L, Beck-Peccoz P. Chronic treatment with inhaled corticosteroids does not modify leptin serum levels. Exp Clin Endocrinol Diabetes. 2003;111(2):77-9. doi: 10.1055/s-2003-39233. [PubMed: 12746757].

14. Farah CS, Salome CM. Asthma and obesity: a known association but unknown mechanism. Respirology. 2012;17(3):412-21. doi:10.1111/j.14401843.2011.02080.x. [PubMed: 21992497].

15. Papoutsakis C, Priftis KN, Drakouli M, Prifti S, Konstantaki E, Chondronikola $\mathrm{M}$, et al. Childhood overweight/obesity and asthma: is there a link? A systematic review of recent epidemiologic evidence. J Acad Nutr Diet. 2013;113(1):77-105. doi: 10.1016/j.jand.2012.08.025. [PubMed: 23260726].

16. Sood A, Shore SA. Adiponectin, Leptin, and Resistin in Asthma: Basic Mechanisms through Population Studies. J Allergy (Cairo). 2013;2013:785835. doi: 10.1155/2013/785835. [PubMed: 24288549].

17. Leivo-Korpela S, Lehtimaki L, Vuolteenaho K, Nieminen R, Kankaanranta $\mathrm{H}$, Saarelainen $\mathrm{S}$, et al. Adipokine resistin predicts antiinflammatory effect of glucocorticoids in asthma. J Inflamm (Lond). 2011;8:12. doi: 10.1186/1476-9255-8-12. [PubMed: 21615949].

18. Mai XM, Bottcher MF, Leijon I. Leptin and asthma in overweight children at 12 years of age. Pediatr Allergy Immunol. 2004;15(6):523-30. doi: 10.1111/j.1399-3038.2004.00195.x. [PubMed: 15610366].

19. Savino F, Fissore MF, Grassino EC, Nanni GE, Oggero R, Silvestro L. Ghrelin, leptin and IGF-I levels in breast-fed and formula-fed infants in the first years of life. Acta Paediatr. 2005;94(5):531-7. doi: 10.1080/08035250510027642. [PubMed:16188739].

20. Shore SA, Schwartzman IN, Mellema MS, Flynt L, Imrich A, Johnston RA. Effect of leptin on allergic airway responses in mice. J Allergy Clin Immunol. 2005;115(1):103-9. doi: 10.1016/j.jaci.2004.10.007. [PubMed: 15637554].

21. Nair P, Radford K, Fanat A, Janssen LJ, Peters-Golden M, Cox PG. The effects of leptin on airway smooth muscle responses. Am J Respir Cell Mol Biol. 2008;39(4):475-81. doi: 10.1165/rcmb.2007-00910C. [PubMed: 18421018]. 
22. Sutherland TJ, Sears MR, McLachlan CR, Poulton R, Hancox RJ. Leptin, adiponectin, and asthma: findings from a population-based cohort study. Ann Allergy Asthma Immunol. 2009;103(2):101-7. doi: 10.1016/S1081-1206(10)60161-5. [PubMed: 19739421].

23. Dixon AE, Johnson SE, Griffes LV, Raymond DM, Ramdeo R, Soloveichik A, et al. Relationship of adipokines with immune response and lung function in obese asthmatic and non-asthmatic women. $J$ Asthma. 2011;48(8):811-7. doi: 10.3109/02770903.2011.613507. [PubMed: 21942353].

24. Jartti T, Saarikoski L, Jartti L, Lisinen I, Jula A, Huupponen R, et al. Obesity, adipokines and asthma. Allergy. 2009;64(5):770-7. doi: 10.1111/j.1398-9995.2008.01872.x. [PubMed: 19210351].
25. Kim KW, Shin YH, Lee KE, Kim ES, Sohn MH, Kim KE. Relationship between adipokines and manifestations of childhood asthma. Pediatr Allergy Immunol. 2008;19(6):535-40. doi: 10.1111/j.13993038.2007.00690.x. [PubMed: 18221467].

26. Sood A, Qualls C, Seagrave J, Stidley C, Archibeque T, Berwick M, et al. Effect of specific allergen inhalation on serum adiponectin in human asthma. Chest. 2009;135(2):287-94. doi: 10.1378/chest.08-1705. [PubMed: 18812451].

27. Guler N, Kirerleri E, Ones U, Tamay Z, Salmayenli N, Darendeliler F Leptin: does it have any role in childhood asthma? J Allergy Clin Immunol. 2004;114(2):254-9. doi: 10.1016/j.jaci.2004.03.053. [PubMed: 15316499]. 